\title{
MANUEL ZAPATA OLIVELLA, LE MUNTU AFRICAIN ET LA DÉCOLONISATION DES IMAGINAIRES ET DES ÉPISTÉMOLOGIES EN AMÉRIQUE LATINE
}

\author{
Clément Animan Akassi \\ (Howard University) \\ https://orcid.org/0000-0001-9012-6173
}

Aux héros noirs des gestes décolonisatrices pour la liberté des peuples latinoaméricains et pour les droits humains/civiques du sujet postcolonial africain, à commencer par le marron brésilien Zumbi dos Palmares...

RÉSUMÉ

Ce travail vise à montrer deux choses. La première, c'est de saisir toute l'importance du tournant postcolonial/afro-décolonial dans la construction d'une contre-épistémologie propre au sujet culturel colonisé africain. En d'autres termes, pour le sujet colonisé, cette contre-épistémologie sert à décoloniser les imaginaires, à partir d'un questionnement de la colonialité de l'épistémologie et du savoir donnés pour universels par l'occident. La deuxième chose, c'est que -à quelques mois de la commémoration du centenaire de la naissance du prolixe et polygraphe auteur africain-colombien Manuel Zapata Olivella (1920-2004) - cet article puisse le situer à sa juste place. Celle d'un sujet culturel colonisé africain des Amériques dont l'abondante production culturelle et la pensée, portées et révolutionnées par le concept de Muntu africain, participent de la décolonisation des imaginaires et de l'épistémologie.

MOTS-CLÉS: Manuel Zapata Olivella; muntu; postcolonialité/(afro-)décolonialité; sujet postcolonial; décolonisation de l'imaginaire. 


\section{MANUEL ZAPATA OLIVELLA, O MUNTU AFRICANO E A DESCOLONIZAÇÃO DOS IMAGINÁRIOS E EPIS- TEMOLOGIAS NA AMÉRICA LATINA}

RESUMO

Este trabalho tem dois objetivos. O primeiro deles é mostrar toda a relevância do giro pós-colonial/(afro)de-colonial na construção de uma contra-epistemologia própria ao sujeito cultural colonizado africano. Dito com outras palavras, para o sujeito colonizado tal contra-epistemologia desempenha a função de descolonizar os imaginários, a partir de um questionamento da colonialidade da epistemologia e do saber ocidentais voltados a uma perspectiva universal. O segundo objetivo é que - quando faltam alguns meses da comemoração ao aniversário do prolixo e poligrafo autor africano-colombiano Manuel Zapata Olivella (1920-2004) - este artigo possibilite colocá-lo em seu merecido lugar. O lugar de um sujeito africano nas Américas, cuja abundante produção cultural e de pensamento era influenciada pelo conceito de Muntu africano. Ao empregar este referencial africano em sua produção cultural, Olivella acaba por desencadear a descolonização dos imaginários e das epistemologias.

PALAVRAS-CHAVE: Manuel Zapata Olivella; muntu; pós-colonialidade/(afro) de-colonialidade; sujeito pós-colonial; descolonização do imaginário. 


\section{MANUEL ZAPATA OLIVELLA, THE AFRICAN MUNTU AND THE DECONOLIZATION OF IMAGERIES AND EPISTEMOLOGIES IN LATIN AMERICA}

\section{ABSTRACT}

This work has two objectives: the first one is to show the full relevance of the postcolonial/ (Afro) decolonized turn into the construction of a counter-epistemology of the colonized African cultural subject. In other words, for the colonized subject, such a counter-epistemology performs the function of decolonizing the imageries by a questioning of the coloniality of the Western epistemology and knowledge turned to a universal perspective. The second objective is that - as it remains a few months to commemorate the birthday of the prolific and polygraph AfricanColombian author Manuel Zapata Olivella (1920-2004) - this article enables to put the writer in the place he deserves to be: the place of an African subject in the Americas, whose abundant cultural and thought production was influenced by the concept of African Muntu. By employing this African framework in his cultural production, Olivella unleashes the decolonization of the imageries and epistemologies.

KEYWORDS: Manuel Zapata Olivella; Muntu; postcoloniality/ (Afro) decoloniality; postcolonial subject; decolonization of the imagery. 


\section{Brefs prolégomènes énoncés hors des frontières de la pensée}

Il me semble d'acuité de commencer cette étude en levant un voile épistémologique. Il s'agit des raisons pour lesquelles la postcolonialité (ou théories postcoloniales) est la matrice théorique de cet essai. Il faudrait tout de suite relever que mon rapport aux théories postcoloniales ne participe pas forcément de la ferveur dont elles bénéficient dans les milieux académiques. J'y vois plutôt ceci : pour la première fois dans l'histoire de la construction des épistémologies, la postcolonialité (ou sa variation, la décolonialité, toutes proportions gardées) semble donner l'occasion au sujet culturel colonisé - ou sujet postcolonial ${ }^{1}-d^{\prime}$ 'articuler une contre-épistémologie/contre-discours propre, débarrassée de la reproduction des discours hégémoniques du sujet culturel colonisateur ou sujet occidental. Cette contre-épistémologie trouve son originalité et inscrit sa rupture dans le fait qu'elle prétend décoloniser les imaginaires et le savoir. En d'autres termes, pour le sujet colonisé (ici, le sujet postcolonial africain), la décolonisation de l'imaginaire s'institue à partir d'un questionnement de la colonialité de l'épistémologie et du savoir donnés pour universels par l'occident. Ce questionnement suggère, par ailleurs, que la contre-épsitémologie proposée n'est pas seulement de l'ordre de l'écriture, mais relève aussi de l'oralité et des gestes du sujet postcolonial africain.

De ce point de vue, on pourrait souligner les gestes des héros et/ ou marrons telles que celles des reines Nzinga (du royaume Kongo et de l'actuel Angola) et Yennenga (du royaume Mossi et de l'actuel Burkina Faso), de Samory Touré (de l'actuelle Guinée-Conakry), Gaspard Yanga (du Mexique), Zumbi dos Palmares (du Brésil), Benkos Biohó (de la Colombie), Dutty Boukman (d'Haïti), etc. À ces gestes, passées sous silence dans les livres d'histoire et dans les imaginaires nationaux, il faudrait convoquer ici aussi 3/4pour ce qui concerne l'Amérique Latine, par exem$\mathrm{ple}^{3 / 4}$ les groupes contemporains de Hip Hop, Hermanos de Causa (Cuba) ou ChocQuibTown (Colombia) dont les chansons sont de véritables interpellations sur l'invisibilisation, la marginalisation et l'exploitation des descendants d'africains. Il me semble précisément que, compte-tenu du fait que ces groupes Hip Hop sont des producteurs de culture comme d'autres, on ne pourrait les réduire à la catégorie de "culture(s)

1 J'y reviendrais. 
populaire(s)", comme c'est le cas souvent dans les discours officiels ou ceux de la doxa (non officiels). Car cela reviendrait à supposer qu'il existerait une culture dominante, celle d'un homo sapiens (sujet dépositaire d'un savoir supposé rationnel et objectif) opposée à la culture d'un homo ludens (sujet supposé "non élitiste" et saltimbanque), dépositaire de ladite culture populaire ${ }^{2}$. Là réside la perversion d'une telle acception, surtout dans le cas des Amériques et particulièrement de l'Amérique Latine où les classes dites populaires se confondent aux races les plus défavorisées (de tous les points de vue) y compris le sujet colonisé/sujet poscolonial africain. Ce qui expliquerait que la culture d'origine africaine supposée populaire soit perçue comme culture de seconde catégorie dans les imaginaires latino-américains. De sorte que le processus d'occultation de l'histoire du sujet colonisé africain devient consubstantiel à la subalternisation de sa production culturelle $\mathrm{e}^{3}$. Il est à noter aussi que, quand il arrive de souligner la contribution de la culture africaine dans la construction des sociétés latino-américaines, la musique et ses avatars (chants, danses, etc.) sont les apports "populaires" les plus cités dans les discours sur les nations. Passant ainsi sous silence toutes les autres contributions à l'économie, la politique ${ }^{4}$, voire àux productions culturelles, y compris la littérature. C'est à la lumière de cela qu'on pourrait mieux comprendre pourquoi un

2 Dans le cas de la Colombie, on pourrait cependant souligner les efforts de déconstruction d'une telle représentation par l'Instituto Popular de Cultura (Institut Populaire de la Culture). Depuis quelques années déjà - même si beaucoup reste encore à faire pour décoloniser les imaginaires - bien de ses dirigeants, y compris, l'actuelle directrice María del Pilar Meza Díaz, tentent une remise en question des tensions apparemment irréconciliables entre le faire et le savoir, l'érudition et le populaire/l'inculture. C'est dans ce contexte qu'il faudrait comprendre la présence - passée ou présente - à l'IPC d'artistes et de chercheurs en arts (sans titres universitaires) reconnus pour leurs expertises dans le champ des pratiques artistiques. Parmi eux, on pourrait citer Delia Zapata Olivella, Lorenzo Miranda et Emilio Bánquez.

3 Culture subalternisée et pas subalterne.

4 En plus de l'inestimable participation (jusqu'au sang) au trésor de l'économie de plantation, le sujet colonisé africain a été la cheville ouvrière de la construction du Canal de Panamá et des chemins de fer du Costa Rica. Ce qui a eu pour mérite de transformer profondément l'économie moderne de ces pays. De Benkós Biohó a Antonio Maceo, ils sont légion les sujets colonisés africains qui se sont soulevés pour les droits civiques et libertés politiques en Amérique Latine. 
auteur et penseur aussi prolixe et polygraphe que Manuel Zapata Olivella ait été moins apprécié que d'autres auteurs (blancs) latino-américains comme Fernando Ortiz (Cuba) et Gabriel García Márquez (Colombie) ${ }^{5}$, par exemple.

Ce travail prétend précisément situer Manuel Zapata Olivella à sa juste place: celle d'un descendant africain des Amériques dont l'abondante production culturelle et la pensée, portées et révolutionnées par le concept de Muntu, participent de la décolonisation des imaginaires et de l'épistémologie. La proéminence de la production culturelle et de la pensée de Manuel Zapata Olivella ne l'autorise donc pas à habiter la frontière de la pensée dominante occidentale et eurocentrique, contrairement à ce que proposent Walter Mignolo et ses épigones pour les penseurs du Sud Global (en opposition au Nord Global/Occidental) ${ }^{6}$. Car, on ne peut à la fois résider dans les marges et (co)-occuper le centre de la pensée.

\section{En guise de précisions conceptuelles sur la pos- tcolonialité, le sujet (culturel) postcolonial africain/sujet de la postcolonie et la décolonisation de l'imaginaire}

Pour mieux aborder la lecture de cet essai, il convient de comprendre par sujet culturel, une instance collective, discursive et idéologique, avec ses propres paradigmes de représentation de soi et du monde. Ce sujet culturel sera prolongé des fois pour donner le sujet (culturel) colonisé voire le sujet (culturel) postcolonial africain ${ }^{7}$. Suivant le même procédé d'interchangeabilité, j'utiliserai à la fois la postcolonialité (fait

5 Dans l'histoire des idées en Amérique Latine, il est recurrent de voir Ortiz présenté comme anthropologue, musicologue, specialiste de musique afro-cubaine, penseur de la nation cubaine, etc. Manuel Zapata Olivella était tout ceci, voire plus (il était aussi médecin, folcloriste, artiste, conteur, panafricaniste, penseur de la politique et de l'identité latino-américaines, etc.) sans que cela ne soit reconnu à sa juste mesure.

Il est de notoriété publique aussi que Manuel Zapata Olivella a été d'une grande influence dans la germination de l'œuvre de Gabriel García Márquez. Nonobstant cela, Zapata Olivella n'est jamais vraiment sorti de l'ombre de sa production culturelle.

6 MIGNOLO, 2015.

7 Parler du sujet culturel africain, c'est ainsi renvoyer à un sujet collectif de race et non à une représentation individuelle. 
colonial), la décolonialité voire les théories postcoloniales pour signifier la même chose.

La postcolonialité est une complexité conceptuelle car elle va bien au-delà de la temporalité affichée par le préfixe "post", comme j'avais eu l'occasion de le dire par ailleurs ${ }^{8}$. C'est cette complexité même qui fixe les limites que je crois percevoir dans l'approche postcoloniale de Homi Bhabha. Dans ses livres Nation and narration (1990) et The location of culture (1994), Bhabha définit les nations postcoloniales comme celles ayant été colonisées, a priori libérées de la directe mainmise territoriale, politique, économique, culturelle du sujet colonisateur. Seulement, la date anniversaire des "indépendances" nationales ${ }^{9}$ ne met pas un terme au fait colonial qui est différent du temps (de la durée) du colonialisme. La postcolonialité outrepasse donc la temporalité du colonialisme pour s'instituer dans l'idéologie/le contre-discours (écrits, pratiques/gestes. oralité, etc). C'est la conscience que le sujet colonisé a toujours eue de soi (et du monde) et qui s'est mis en ordre d'opposition dès l'instant même (esclavage et colonisation) où le sujet colonisateur commence à l'imaginer et lui nier son humanité. Il en résulte que la notion de sujet postcolonial africain va s'inscrire dans l'idéologique (comme représentation) et non dans la temporalité des après-indépendances. Du moins, pas exclusivement comme le laisserait supposer le sujet postcolonial des nations postcoloniales proposées par Bhabha.

À la suite d'Homi Bhabha, on pourrait citer des apories majeures aussi chez Walter Mignolo, l'un des penseurs les plus proéminents des théories postcoloniales, surtout si on s'en tient aux thèses posées par le courant et le tournant décolonial qu'il semble incarner. Il reste que la complexité de la postcolonialité - et du sujet postcolonial qui en est le résultat - montre bien que chez lui aussi, il existe des limites bien insurmontables. En effet, l'un des remarquables apports de Mignolo aux théories postcoloniales/décoloniales, c'est d'avoir parlé de certaines figures de cette conscience africaine de soi telles que Ottoba Cugoano et Elodah Equiano (deux africains connus pour leurs gestes et visions d'abolicionnistes dans les colonies de l'empire anglais) ou encore Frantz Fanon, pour ne citer que ceux-là et pour faire vite. À grands traits, on pourrait résumer

8 AKASSI, 2010, p. 19-32; 2015, s.p.

9 Le désenchantement de ces indépendances est bien transcrit par d'Ahmadou Kourouma dans son premier roman, Les soleils des indépendances (1968). 
la pensée décoloniale de Mignolo (et de ses épigones ou condisciples ${ }^{10}$ ) de la manière suivante: il y aurait un tournant dans l'histoire de la pensée humaine, car l'émergence d'une épistémologie ou d'un contre-discours émanant du Sud Global/non-occidental serait en train d'ébranler les fondements du perpétuel logos/discours colonial du Nord Global/monde occidental ayant $(\mathrm{eu})$ vocation à dominer toute autre forme de pensée. En outre, dans l'épilogue à Habitar la frontera, livre-recueil de ses pensées, Mignolo insiste sur la nécessité d'une pensée et d'un savoir (construits dans les démarcations) des frontières pour mettre fin au monopole occidental en la matière $(2015$, p. 457-466). Tout ce qui précède, on le voit, situe Mignolo au centre des figures de la rupture épistémologique proposée par les théories postcoloniales/décoloniales. Cependant, la thèse de la pensée et du savoir des frontières traîne aussi le boulet de deux apories. La première, c'est la difficulté que pourrait avoir le sujet postcolonial à habiter les frontières, puisqu'il serait contradictoire de vouloir co-occuper le centre monopolisé par le sujet occidental/colonisateur et résider à la fois dans les marges. La seconde limite à la proposition décoloniale/postcoloniale de Mignolo, c'est de suggérer que le Sud Global ne serait régi que par une (seule) frontière homogène au-delà de laquelle se situerait le Nord Global. Or, le Sud Global est une constellation de frontières - dont celles de l'Amérique Latine (d'où est originaire Mignolo) - où les conflits (socio-)raciaux donnent à voir, à bien d'égards, la reproduction de l'épistémologie et des pratiques dominantes occidentales/du Nord Global. De ce point de vue, le sujet postcolonial/décolonial/du Sud Global - contrairement à la thèse de Mignolo - devrait être plutôt un sujet qui cherche à sortir de la frontière où le confine le Nord Global et à s'affranchir aussi des multiples barrières dans lesquelles il est tenu pour dominé à l'intérieur même du Sud Global. Et des fois, jusqu'à l'intérieur des frontières du Nord Global (exemple du sujet postcolonial africain aux Etats-Unis ou en Europe, etc.).

Face à toutes ces apories, il me semble que les approches croisées d'Achille Mbembe et d'Edmond Cros semblent être les plus achevées et les plus cohérentes, quant à la façon dont elles posent la question du

10 Sans être exhaustif, on pourrait citer Francisco Carballo, Luis Alfonso Herrera et Ramón Grosfoguel. Même si les prises de position politique de Grosfoguel (notamment en faveur des revolutions cubaines et vénézuéliennes) l'ont éloigné de Walter Mignolo et d'Aníbal Quijano considérés comme la "droite décoloniale". 
sujet postcolonial, sujet indubitablement complexe. En effet, dans D'un sujet à l'autre. Sociocritique et psychanalyse, Cros analyse/définit dans l'un de ses chapitres la notion du sujet culturel postcolonial (1995, p. 4157). Pour lui, ce sujet (latino-americain et/ou africain) est le produit de la violente relation entre le sujet culturel colonisé et le sujet culturel colonisateur. C'est un sujet à la fois indissociable et diffracté. Sujet postcolonial indissociable - pour s'en tenir par exemple à l'Amérique Latine qui semble être le point de départ de l'analyse de Cros - parce qu'il serait à la fois sujet colonisateur (blanc/européen/occidental) et sujet colonisé (africain/ amérindien/non-occidental). Pour traduire les termes de Cros, je dirais que vu de l'Europe ou des Etats-Unis, le sujet postcolonial ne serait au mieux qu'un latino-américain (langage politiquement correct) et au pire, un sudaca (représentation péjorative en Espagne et des fois, en France) ou un latino/hispano (catégorie socio-raciale péjorée aux Etats-Unis). Le sujet postcolonial serait diffracté aussi parce que c'est un sujet traversé par les antagonismes du sujet colonisé et du sujet colonisateur. À supposer le cas une fois encore des Amériques (y compris l'Amérique Latine), ce que dit Cros renverrait aux antagonismes des races en présence (blanc, noir et/ou amérindien). Étant entendu que le sujet colonisateur (blanc/ européen/occidental), en position de dominant, reproduit les discours et pratiques de représentation/domination hérités de la colonisation. D'où la colonialité ou survivance du pouvoir du sujet colonisateur en conflit avec le sujet colonisé.

Il est à noter que c'est dans le même ordre d'idées que se situe Achille Mbembe, philosophe et penseur postcolonial africain. Dans son livre De la postcolonie (2000), il aborde la question de la postcolonialité/ la postcolonie tout en donnant à voir la spécificité du sujet postcolonial africain/sujet de la postcolonie. Mbembe souligne dans son essai que le sujet postcolonial africain/sujet de la postcolonie n'est pas seulement un sujet de fraternité partagée (entre tous les africains), et par là-même, un sujet indissociable. Mais, le sujet postcolonial africain est aussi un sujet de domination, c'est-à-dire un sujet en position de domination vis-à-vis de ses propres frères (africains) et dont l'attitude renverrait à l'image que décrit Mbembe comme celle de «frère-ennemi» et qui recoupe la notion de sujet postcolonial diffracté de Cros.

En dernières instances, le sujet postcolonial ou de la postcolonie, tel qu'articulé par Mbembe et Cros, me semble d'un indubitable intérêt et d'une efficacité certaine pour aborder la trame centrale de cet essai 
tout dédié à Manuel Zapata Olivella, auteur polygraphe et penseur/sujet postcolonial africain de Colombie. L'intérêt pour les ancrages de Cros et Mbembe est mû par le fait que ceux-ci ( $m$ ')amènent à bien montrer que l'émergence du concept africain de Muntu chez Zapata Olivella ne contribue pas seulement à décoloniser les imaginaires et l'épistémologie du Nord Global/Occidental, mais aussi et surtout à signaler la fin du monopole de la pensée dominante (blanche/occidentale) reproduite à l'intérieur même des frontières latino-américaines, voire colombiennes.

\section{Manuel Zapata Olivella : décoloniser les imagi- naires comme sujet postcolonial et penseur du Muntu}

111.1 Manuel Zapata Olivella comme sujet postcolonial africain et intellectuel/co- dépositaire du savoir latino-américain/colombien

Il faudrait mentionner tout de suite que Manuel Zapata Olivella, comme sujet culturel d'ascendance africaine, est un sujet postcolonial porteur d'une représentation de soi et du monde. Et qui, comme tel, s'est toujours refusé à inscrire la construction de l'identité, de la mémoire et du savoir latinoaméricains/colombiens, du seul point de vue de la reproduction de la pensée et de l'épistémologie du sujet colonisateur (blanc latino-américain/colombien).

Jusqu'à sa mort, en 2004, Manuel Zapata Olivella était - et laisse encore à quelques mois du centenaire de sa naissance (1920) - une source intarissable de pensée théorique et politique, de savoir anthropologique, littéraire, médical, musical/folkloriste (au sens du folklore comme culture tout court, non comme représentation coloniale de l'anti-/sous-culture), etc. De sorte que s'intéresser à l'héritage de Zapata Olivella, c'est d'une part reconnaître son statut de baobab, c'est-à-dire de source à la fois d'une mémoire collective latino-américaine/colombienne et d'une mémoire africaine que la mémoire collective ne cesse précisément de convertir en palimpseste, autrement dit, de raturer ou de réécrire. D'autre part, il s'agit de montrer que les discours de Zapata Olivella remettent en question tout le mécanisme de raturage de la mémoire africaine dans la représentation des nations et des identités latino-américaines/colombiennes. 
Au fond, ce qui est en jeu ici, c'est de bien voir qu'en amont de la pensée polyforme de Zapata Olivella se trouve un sujet postcolonial africain - a priori indissociable du sujet culturel blanc (et/ou amérindien) - cofondateur des nations latino-américaines et co-dépositaire de ses mémoires et identités. Or, cela contraste avec les pratiques en vigueur où il est manifeste un monopole de la pensée, des discours et des mémoires par le sujet colonisateur blanc. C'est ce processus de monopole et de représentations perverties du sujet colonisé africain - ou de raturage de sa mémoire - que je nomme la colonisation de l'imaginaire. Dans le contexte latino-américain/colombien, c'est ce monopole - accompagné de coercition voilée ou affichée ${ }^{11}-$ qui fait qu'on puisse monter en étendard les notions de mestizaje/métissage, de démocratie raciale ou encore de transculturation sans qu'on interroge le blanchiment de la société qui fonde une/ de telle(s) notion(s). Or, l'un des mérites de Zapata Olivella c'est d'avoir proposé un contre-discours à l'idée même des nations latino-américaines telles que pensées par le sujet culturel colonisateur/blanc. Dans son essai, Las claves mágicas de América (raza, clase y cultura), Zapata Olivella postule que la colonisation dans les Amériques a créé une nouvelle race d'hommes sans âmes, sauvages et barbares dans l'imaginaire du sujet colonisateur européen (1989, p. 13). Ces hommes-là, on s'en doute, étant le sujet culturel africain (et le sujet culturel amérindien). La toile de fond chez Zapata Olivella, comme l'indique d'ailleurs le dernier chapitre du livre, c'est un questionnement de la pensée de José Vasconcelos, l'un des tenants du discours sur le métissage (latino-)américain. Vasconcelos, philosophe, éducateur et politique mexicain, est aussi (col)porteur culturel et idéologique du sujet colonisateur blanc de son temps, les années $30 \mathrm{du}$ siècle dernier. Dans son essai, Zapata Olivella vient donc contredire la thèse perverse proposée par Vasconcelos concernant le métissage (latino-) américain transcrit par le concept d'"homme cosmique" (1989, p. 179) ${ }^{12}$. Car il était hors de question pour Vasconcelos de compter avec les biens meubles/le sujet colonisé africain pour conformer cette identité cosmique. D'autant que, pour lui, leur contribution aux nations (latino)-américaines

$11 \mathrm{La}$ coercition peut aller jusqu'aux voix inaudibles sur de puissants appareils idéologiques (école, radio, télévision, journaux, etc.), au parlement, dans des maisons d'édition qui ne publieraient pas des œuvres "mineures", etc.

12 En écho à l'essai de José Vasconcelos, La raza cósmica, publié pour la première fois en 1925 mais dont les multiples éditions postérieures abondent. 
serait nulle $\left(1989\right.$, p. 179) ${ }^{13}$. Je crois percevoir que ce que dénonce Zapata Olivella, ce serait donc la propension de Vasconcelos d'exhiber le multiple (de toutes les races en présence) pour mieux le cacher, le fondre dans le moule d'un seul sujet démélanisé/colonisateur, et prétendument porteur d'une civilisation supérieure. Il me semble aussi que ce que remet en cause Zapata Olivella, ce n'est pas l'idée même de métissage puisqu'il le revendique lui-même (1989, p. 180). Il s'insurge plutôt contre un discours dominant aux visées racistes mais qui se targue de parler de métissage. La diffraction du sujet postcolonial latino-américain (Zapata Olivella $v s$ Vasconcelos) situe la prise de parole de Zapata Olivella au cœur d'une décolonisation de la pensée, désormais partagée par les sujets culturels en présence, et non seulement par le sujet colonisateur blanc. Ici, Zapata Olivella subsume le sujet colonisé africain et en fait désormais le co-dépositaire du discours, du savoir et de la pensée sur l'identité/les identités en Amérique Latine. Car, la monumentale œuvre de Zapata Olivella que la tyranie des pages contées nous interdit de déployer dans toute son étendue ici - vient rappeler et démontrer que le sujet postcolonial latinoaméricain/colombien est un sujet appelé à co-fonder la nation/des nations en convoquant de façon indiscriminée les mémoires et identités relevant d'histoires et d'origines différentes.

\subsection{Manuel Zapata Olivella, un penseur postcolonial}

Malgré la pertinence de sa prolixe production, Manuel Zapata Olivella n'est pas reconnu au panthéon du savoir et de la pensée au même titre que ses pairs (blancs) Fernando Ortiz de Cuba ou Gabriel García Márquez de la Colombie. Même si des efforts (politiques et symboliques) sont en train d'être faits pour commémorer 2020 comme l'Année Manuel Zapata Olivella", il reste que le peu de place qui lui est fait dans les institutions académiques, les librairies ou encore les maisons d'édition traduit tout de même une injustice. D'autant que Zapata Olivella peut être inscrit dans la généalogie des penseurs postcoloniaux. Il suffit pour le démontrer de citer quelques unes de ses productions en dialogue direct ou indirect avec des œuvres d'auteurs contemporains (du XXe siècle). En effet, quand Zapata Olivella publie Tierra Mojada (1947) et particulièrement

13 Dans El fusilamiento del diablo (1999) et El árbol brujo de la libertad (2014), Zapata Olivella procède aussi à la déconstruction d'une telle représentation du sujet colonisé africain. 
Pasión vagabunda (1949), c'est dans le contexte national de la parution de Tambores en la noche (1940) de Jorge Artel et de Las estrellas son negras (1949) de Arnaldo Palacios. Au niveau international, sont parus avant ou après - plusieurs livres de Langston Hughes ${ }^{14}$, ainsi que Color and Democracy (1945) de William E.B. Dubois, Motivos de son (1930) de Nicolás Guillén, Cahier d'un retour au pays natal (1939), Discours sur le colonialisme (1950) d'Aimé Césaire, Peau noire, masques blancs (1952) et Les damnés de la terre (1961) de Frantz Fanon. La décade des années 30 qui précède celle des années 40 est particulièrement chargé d'un sens à mettre en relief. Le mouvement africain américain du Harlem Renaissance vient en contrepoint de la lointaine - mais toujours structurante renaissance européenne, mouvement à la remorque de l'impérialisme, de l'esclavagisme et de la colonisation dans lesquels il surgit. Le contrepoint de Harlem Renaissance étant par là même la renaissance des arts et de la dignité du sujet culturel colonisé africain. L'influence de ce mouvement s'étendra jusqu'en France où Aimé Césaire, Léopold Sédar Senghor et Léon Gontran Damas, co-fonderont à leur tour le mouvement de la Négritude, dont le pendant latino-américain, le Negrismo, sera l'œuvre pionnière de Nicolás Guillén (Cuba). Plus tard, avec Peau noire et Les damnés, Frantz Fanon - theóricien du renversement de la violence épistémique - finira par être la figure africaine/diasporique la plus tutélaire dans la généalogie des théories postcoloniales. Zapata Olivella ne tissera pas que des rapports personnels avec Léopold Sédar Senghor, Aimé Césaire, Léon Gontran Damas, Nicolás Guillén, Abdias do Nascimento, Frantz Fanon, voire avec Jorge Artel et Arnoldo Palacios. Il partagera avec eux aussi cette visée postcoloniale de décoloniser l'épistémologie en commençant par introduire la notion de race (noire) dans le discours classiste du marxisme. Comme eux, Zapata Olivella viendra à substituer la lutte des classes par la lutte des races, classes et races se confondant dans les Amériques et dans les métropoles d'accueil du sujet colonisé africain. C'est ce qu'il transcrit une fois encore dans Claves mágicas et particulièrement dans le chapitre "La lucha de Razas y Clases en las Guerras de Independencia y la República" (1989, p. 147-178). Là, il semble se dégager l'idée que la lutte (socio-)raciale s'imposait par le confinement dont est objet le sujet colonisé

14 Activiste, poète, noveliste, dramaturge, éditorialiste et connu pour être l'un des pionniers du mouvement africain américain de Harlem Renaissance aux États-Unis. 
africain (et amérindien) considéré comme citoyen de seconde classe. Et, je crois voir dans ce positionnement idéologique et théorique, la mise à distance definitive entre Zapata Olivella et Gabriel García Márquez dont le silence sur la question du sujet culturel africain en Colombie/Amérique Latine a souvent été patent.

111.3. Le Muntu, paradigme africain de la narration zapatienne de la nation colombienne ou des nations latino-américaines

Le Muntu est à la fois un mot et une philosophie d'origine africaine. Il est synonyme de Ubuntu qui signifie en Zoulou, "je suis parce que nous sommes" ou encore "mon humanité existe parce qu'existe la tienne". En Swahili, le Muntu se refère à Umoja qui signifie "unité".

Dans Changó, el gran putas (1983) - le livre qui devrait achever de placer son auteur au panthéon de la production culturelle colombienne, latino-américaine et universelle -, Zapata Olivella se réapproprie le Muntu pour servir ses discours sur la culture, la mémoire, la nation et/ou l'identité, y compris, celle du sujet colonisé africain en Amérique Latine/Colombie. En guise d'illustration, commençons par la première page de la première partie du roman :

¡Oídos del Muntu, oíd!

¡Oid! ¡Oid! ¡Oid!

¡Oídos del Muntu, oíd!

(La kora ríe

lloraba la kora, sus cuerdas hermanas narrarán un solo canto la historia de Nagó el trágico viaje del Muntu al continente exilio de Changó).

Soy Ngafúa, hijo de Kissi-Kama.

Dame, padre, tu voz creadora de imágenes, tu voz tantas veces escuchada a la sombra del baobab.

¡Kissi-Kama, padre, despierta!

Aquí, te invoco esta noche, Junta a mi voz tus sabias historias. ¡Mi dolor es grande (2010, p. 43). 
Ce passage est significatif pour le doute historique qu'il lève. Il s'agit de la persistente idée que le sujet colonisé africain de Colombie (voire d'Amérique Latine) ne serait que d'origine bantoue sans que les raisons d'une telle affirmation ne soient vraiment élucidées. Car, les hérauts d'une telle idée ne se rendent pas comptent que le Cameroun, le Nigéria ou le Tchad, considérés comme pays/peuples bantous sont habités aussi par des haoussas qui ne sont ni de la forêt dense (où résideraient les bantous), ni n'ont de langues d'origine bantoue ${ }^{15}$. C'est donc ce processus de nommer faussement et réécrire l'histoire pour mieux coloniser les imaginaires que le roman épique, Changó, vient démanteler. Cette première page est ainsi informée par de multiples mémoires africaines dont celles des mandingues, et plus loin dans les pages suivantes du livre, des ewés/fons, ashantis, nagos/ yorubas. À la lumière de ce qui précède, il me semble que, pour Zapata Olivella, parler du sujet colonisé africain en Colombie/Amérique, ce n'est pas seulement se référer à une seule origine africaine (comme si toute l'Afrique fût un continent-pays-bantou), sinon à la diversité de ses origines (ethniques et linguistiques), toutes liées par la même histoire ancestrale, puis par l'esclavage et la colonisation. Le dire, c'est montrer par ailleurs l'étendue de la violence structurelle et de l'imaginaire qui a dévasté toute l'Afrique et pas seulement une partie du continent, ni une partie de ses peuples.

À commencer par sa première page, Changó pose donc Muntu comme le destinataire de l'histoire du sujet colonisé africain. L'histoire de son glorieux passé, de Soundjata à Benkos Biohó, enseveli par la traversée, puis par l'esclavage. Muntu devient ainsi l'oreille à qui l'instance narratrice/griot conte son humanité 3/4dépositaire d'une histoire, d'une cosmogonie, d'un savoir/d'une pensée et de valeurs. Une humanité construite et transmise dans/par l'oralité, mais qui n'en démeure pas moins une, face à la grammaire écrite et résolument impérialiste du sujet colonisateur blanc/européen/occidental ${ }^{16}$.

En echo aux vers de "Souffles" (1960), de l'écrivain sénégalais Birago Diop, où "les morts ne sont pas morts", le Muntu se déploie aussi dans Changó pour servir de lien entre les vivants et les morts, revendiquant ainsi une croyance religieuse bien africaine qui convoque dans le

15 Quoique là encore, la taxinomie des langues d'origine bantoue reste à débattre. 16 Les raisons de l'émergence de la grammaire espagnole ont des relents impérialistes explicites telles qu'exposées par Antonio de Nebrija à la reine Isabel La Catholique. On se rappelera que cette grammaire se construit dans l'année de la volente conquête de l'Amérique. 
texte aussi bien Changó que les autres dieux-ancêtres africains appelés orichas dans le texte. De ce fait, le Muntu sert à déconstruire la dichotomie mort $v s$ vivant en vigueur dans les religions judéo-chrétiennes qui tiennent lieu de religions officielles en Amérique Latine/Colombie. Mais, ce questionnement de la foi judéo-chrétienne ne suggère pas son exclusion de l'autel des croyances - comme invite à le faire le marxisme qui y voit l'opium du peuple -, il interpelle plutôt sur la fin de la hiérarchisation de la foi, surtout dans un contexte où les sujets colonisateur blanc et colonisé africain (et/ou amériendien) sont co-fondateurs des nations latino-américaines.

Larvé ou explicite, le Muntu est fondamentalement un concept central qui parcourt la production culturelle de Zapata Olivella (essai, textes littéraires, etc.), y compris dans Tierra Mojada, Las claves mágicas, La rebelión de los genes (1997) et El árbol brujo de la libertad (2014). Mais sa forme la plus achevée reste sans doute celle exposée dans Changó. Dans cette œuvre magistrale, qui transcende les genres, on peut voir comment le Muntu s'inscrit aussi dans la perspective postcoloniale (ou afro-décoloniale) comme une contre-épistémologie/contre-discours. Voyons, de ce point de vue, comment Zapata Olivella se démarque, par exemple, de García Márquez, dans le champ de la littérature et des discours sur la nation colombienne ou les nations latino-américaines. Il est désormais bien admis que García Márquez, dans Cien años de soledad (1967), a transcrit la problématique de la violence structurelle de la fondation de la Colombie/ l'Amérique Latine, à partir de référents judéo-chrétiens qui auraient donné une dimension universelle à son roman. En effet, dès les prémices de Cien años, l'instance narratrice déclare justement que l'univers ambiant était si vierge qu'il fallait commencer par lui donner vie. À partir de ce moment, ce monde-là - à l'image de la Colombie/l'Amérique Latine - se peuple de tous les sujets culturels (blanc, amérindien) sauf du sujet culturel colonisé africain. Passons même sur cette allusion à la terre vierge qui reproduit la thèse coloniale de la "découverte" de terres déjà habitées, et remarquons que la nation colombienne est pensée dans Cien años sans la mémoire et le protagonisme du sujet culturel colonisé africain rendu invisible.

Au contraire de García Márquez, avec qui il partage une certaine complicité en privé17, Zapata Olivella propose un autre discours littérai-

17 Mais, là n'est pas la question, contrairement à ce que certains thuriféraires de García Márquez pensent. Pour ces derniers, l'amitié entre García Márquez (un blanc) et Zapata Olivella (un noir) devrait suffire à absoudre García Márquez sur 
re sur la nation colombienne et les identités (latino-)américaines. Dans Tierra mojada déjà, le sujet colonisé africain est un prolétaire/paysan dont l'origine africaine est bien soulignée. Car, comme je l'avais mentionné plus haut, la lutte de classes dans les Amériques est consubstantielle à la lutte des races pour le sujet colonisé africain. En même temps, elle transcrit le protagonisme du sujet colonisé africain dans les changements sociaux en Colombie/Amérique Latine. Plus tard, dans Changó, la culture du sujet colonisé africain viendra informer la théorie du Muntu qui fera de ce sujet le porteur d'une contre-épistémologie/contre-discours sur les identités en Amérique (Latine)/Colombie :

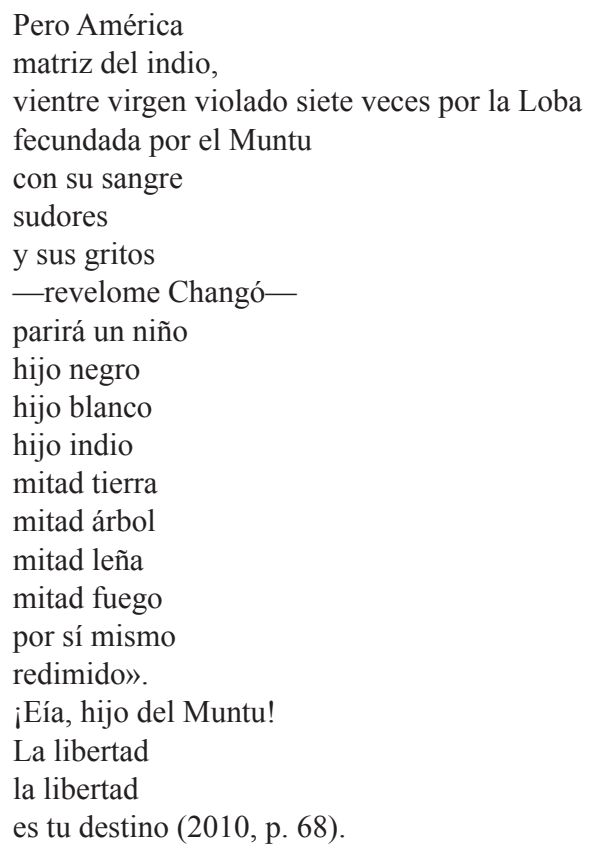

Ici, le Muntu africain, proposition épistémologique de Zapata Olivella, est une théorie du passage et de l'incarnation. C'est une voie de décolonisation de l'imaginaire, car c'est le passage de l'histoire désincarnée au corps de l'histoire du sujet colonisé africain, de son incarnation par le sang (versé), la sueur et les cris (de la souffrance). C'est le corps tout

ses silences littéraires sur le sujet colonisé africain. 
entier dressé - et non courbé, animalisé, réduit à néant - pour la liberté de soi (le sujet culturel africain) et des autres (sujets culturels amérindien et blanc). C'est un corps noir qui féconde les Amériques et par là même, est la promesse de la naissance d'un nouveau corps desormais débarrassé de toute pureté originelle : à la fois fils/fille de noir, de blanc et d'amérindien. Cette fraternité proposée par le Muntu africain est bien un projeté de fraternité incarnée, en situation historique d'indiscrimination, tout à fait aux antipodes de celle proposée par la révolution française - en pleine période d'esclavage - ou par les sociétés (latino-)américaines où persiste encore aujourd'hui la discrimination raciale.

En réalité, au-delà du discours - médiatisé par la théorie muntusur les identités colombiennes et (latino-)américaines, la préoccupation constante de Zapata Olivella a toujours été une réflexion plus large sur l'Amérique-continent (ou Amériques) comme lieu de dissémiNations de plusieurs et diverses cultures/races. Et non de hiérarchie des races, dominée par le sujet colonisateur blanc. À cet égard, les dernières lignes de " $E l$ hombre americano", dans Claves, sont édifiantes puisque,

Finalmente sabemos, por mirar atrás y al futuro, que el americano es (...) la refundición de muchos pueblos, el antirracista ontogénico: su destino es afirmarse en el maridaje de todas las sangres" (1989, p.180)

(Finalement, nous savons que, eu égard au passé et au futur, l'américain est (...) le creuset de plusieurs peuples, de l'anti-racisme ontogénique : son destin est de s'affirmer dans le mariage de tous les sangs $\left.{ }^{18}\right)$.

Zapata Olivella va plus loin. D'autant qu'il me semble que l'idée d'Amérique-continent ne répond pas seulement à un souci de dépassement du localisme colombien ou des regionalisms latino-américains. Il s'agit bien d'un processus de décolonisation de l'imaginaire en rapport avec le concept de latinité/latino (1989, p. 180) qui suppose, par ses origines latines/européennes/romaines, un laisser là, dans les marges de la langue et de l'histoire, le sujet colonisé africain (et/ou amérindien). De sorte que renvoyer à l'Amérique-continent, et non à l'Amérique Latine, c'est donner corps à une histoire, l'incarner avec toutes ses langues-cultures et tous ses membres - au nom d'un triple devoir de mémoire (noire, amérindienne, blanche) - et non l'imaginer en la désincarnant injustement, comme c'est le cas aujourd'hui encore.

$18 \mathrm{La}$ traduction est de moi. 


\section{RÉFÉRENCES}

AKASSI, Animan Clément. Introducción. Discursos poscoloniales y renegociaciones de las identidades: Áfricas, Américas, Caribes, Europa. Perpignan: Presses Universitaires de Perpignan, 2010. p. 19-32.

. El sujeto (pos)colonial y de la poscolonia: ¿hacia una crítica literaria para los estudios hispanoafricanos? Sociocriticism, v.xxv, n.1-2, p. 329-351, 2010.

. Contradiscurso sobre la negrofobia y renegociación de la hispanidad en los textos del exilio de Gastón Baquero. Líneas, n.5, s.p., 2015. Disponible sur: https://revues.univ-pau.fr/lineas/1519. Consulté le 28 août 2019.

BHABHA, Homi, ed. Nation and Narration. London: Routledge, 1990.

BHABHA, Homi. The location of culture. London and New York: Routledge, 1994.

CROS, Edmond. D'un sujet à l'autre. Sociocritique et psychanalyse. Montpellier: CERS, 1995.

DIOP, Birago. Leurres et Lueurs. 2. ed. Paris: Présence Africaine, 2000.

DO NASCIMENTO, Abdias. O genocidio do negro brasileiro. 2. ed. São Paulo: Perspectiva, 2016.

FANON, Frantz. Peau noire, masques blancs. Paris: Points, 2012 (Seuil, 1952).

Les damnés de la terre. Paris: La Découverte, 2004 (Maspéro, 1961).

FREYRE, Gilberto. Casa-grande e senzala. 34. ed. Rio de Janeiro \& São Paulo: Record,1998.

GARCÍA MÁRQUEZ, Gabriel. Cien años de soledad. Madrid: Cátedra, 2007 (Sudamericana, 1967).

LOUIS GATES, JR., Henry. Black in Latin America, DVD, 2011. Disponible sur <https:/www.youtube.com/watch? $\mathrm{v}=\mathrm{Gh} 7 \mathrm{c} 46 \mathrm{U} 5 \mathrm{hhY} \&$ list=PLwbQCdHvOO GHBDtDiezFvXzUkJgEWFO8Z>. Consulté le 28 août 2019.

MBEMBE, Achille. De la postcolonie. París: Karthala, 2000.

. Critique de la raison nègre. Paris; La Découverte, 2013.

MIGNOLO, Walter. Habitar la frontera. Sentir y pensar la descolonialidad (Antología, 1999-2014). Prólogo y selección de Francisco Carballo y Luis Alfonso Herrera Robles. Barcelona: CIDOB \& UACI, 2015.

ORTIZ, Fernando. Contrapunteo cubano del tabaco y el azúcar. Caracas: Biblioteca Ayacucho, 1987 (Editorial Jesús Montero, 1940). 
ZAPATA OLIVELLA, Manuel. Tierra Mojada. Nueva edición de prueba. Cali: Universidad del Valle, 2018 (Espiral, 1947).

Changó el gran putas. Bogotá: Ministerio de Cultura, 2010 (Oveja Negra. 1983).

El fusilamiento del diablo. 2. ed. Bogotá: Plaza \& Janés. 1999.

Las claves mágicas de América (Raza, Clase y Cultura). Bogotá: Plaza \& Janés, 1989.

La rebelión de los genes. EI mestizaje americano en la sociedad futura. Bogotá: Altamir, 1997.

Recebido em: 02/09/2019

Aceito em: 30/09/2019 